\title{
Treatment of metastatic spinal epidural disease: a review of the literature
}

\author{
Paul Klimo, Jr., M.D., M.P.H., John R. W. Kestle, M.D., M.Sc., \\ AND MEIC H. SCHMIDT, M.D. \\ Department of Neurosurgery, University of Utah, Salt Lake City, Utah
}

\begin{abstract}
Object. Spinal cord compression is one of the most dreaded complications of metastatic cancer. It can lead to a number of sequelae, including pain, spinal instability, neurological deficits, and a reduction in the patient's quality of life. Except in selected circumstances, treatment is palliative. Treatment options include surgery, radiation, and chemotherapy. The goal of this study was to summarize the existing data on the outcomes of various treatment methods for metastatic spinal epidural disease and to make appropriate recommendations for their use.

Methods. The authors used a search strategy that included an electronic database search, a manual search of journals, analysis of bibliographies in relevant review papers, and consultation with the senior author. There is good evidence, including Class I data, that steroid drugs constitute a beneficial adjunctive therapy in patients with myelopathy from epidural compression. Historically, conventional radiation therapy has been viewed as the first-line treatment because it has been shown to be as effective as a decompressive laminectomy, with a lower incidence of complications (Class II data). Nevertheless, in the last 20 years there has been remarkable progress in surgical techniques and technology. Currently, the goals of surgery are to achieve a circumferential decompression of the spinal cord, and to reconstruct and immediately stabilize the spinal column. Results in a large body of literature support the belief that surgery is better at retaining or regaining neurological function than radiation and that surgery is highly effective in relieving pain. Most of the data on the treatment of metastatic spinal disease are Class II or III, but the preliminary results of a well-designed, randomized controlled trial in which surgery is compared with standard radiation therapy represents the first Class I data.

Conclusions. As the number of treatment options for metastatic spinal disease has grown, it has become clear that effective implementation of these treatments can only be achieved by a multidisciplinary approach.
\end{abstract}

\section{KEY WORDS - spine • metastasis - radiation therapy • stereotactic radiosurgery}

In approximately 50 to $70 \%$ of patients with cancer there is evidence of metastatic disease at the time of death. ${ }^{36}$ The spinal column is the most common osseous site, and may be involved in up to $40 \%$ of patients with cancer. ${ }^{11,89}$ Not all spinal metastases will lead to neurological dysfunction, however. Epidural spinal cord compression from metastases occurs in 5 to $10 \%$ of cancer patients and in up to $40 \%$ of patients with preexisting nonspinal bone metastases. ${ }^{6,8,15,26,38,89}$ Of those with spinal disease, 10 to $20 \%$ will experience symptomatic spinal cord compression, resulting in more than 25,000 cases per year; this number is expected to grow. ${ }^{28,50,72}$

The thoracic spine is the most common site of disease $(70 \%)$, followed by the lumbar $(20 \%)$ and cervical spine (10\%). ${ }^{15,28,29}$ Metastatic spinal disease can arise from one of three locations: the vertebral column $(85 \%)$, the paravertebral region (10-15\%), and, rarely, the epidural or subarachnoid/intramedullary space itself $(<5 \%){ }^{15,28,29}$ The posterior half of the VB is usually involved first, with the anterior body, lamina, and pedicles invaded later. ${ }^{1}$ In-

Abbreviation used in this paper: $\mathrm{VB}=$ vertebral body. tradural (including intramedullary) metastases from nonneural primary tumors are extremely rare, but have been reported. ${ }^{41,73}$ Multiple lesions at noncontiguous levels occur in 10 to $40 \%$ of cases. . $^{15,19,28,29}$

Approximately $50 \%$ of spinal metastases arise from one of three primary sites: breast, lung, or prostate. ${ }^{15}$ These are followed by renal, gastrointestinal, thyroid, sarcoma, and the lymphoreticular malignancies lymphoma and multiple myeloma. Metastases from prostate, breast, melanoma, and lung lesions commonly cause spinal tumors in $90.5,74.3,54.5$, and $44.9 \%$ of patients, respectively. ${ }^{89}$ The incidence of neurological deficits caused by epidural spinal cord compression varies, however, with the site of primary disease as follows: $22 \%$ of patients with breast cancer, $15 \%$ with lung cancer, and $10 \%$ with prostate cancer. ${ }^{28}$ In the past, neurological dysfunction and spine pain would have been the first manifestation of their cancer in up to $70 \%$ of patients. ${ }^{13,14,79,82}$ In these cases, the lung was the primary source of malignancy more than $50 \%$ of the time. ${ }^{28,79}$

Treatment for spinal metastases is frequently palliative. Only in selected cases, usually with renal cell carcinoma, 


\section{P. Klimo, J. R. W. Kestle, and M. H. Schmidt}

can cure be the goal if the spine is the only known site of disease. ${ }^{12}$ Treatment can be broadly categorized as chemotherapy, radiation, and surgery. In this article we summarize the existing data on these treatment modalities and provide appropriate recommendations on their indications.

\section{CLINICAL MATERIAL AND METHODS}

\section{Search Strategy}

The goal of the search strategy was to identify articles in which the effectiveness of various treatments for metastatic spinal disease, specifically surgery, radiation, and chemotherapy (steroid drugs only) is assessed. The search strategy included an electronic database search, a manual search of journals, analysis of bibliographies in relevant review papers, and consultation with the senior author (M.H.S.). For the electronic search we used Medline (PubMed) to identify articles published between 1966 and August 2003 in which the following terms were used in various combinations: "spine," "metastases," "radiation," "surgery," "steroids," "treatment," "cancer," "decompression," "laminectomy," "stereotactic radiosurgery," and "vertebrectomy." Papers were also found using the "Related Articles" function on PubMed. Articles were reviewed and the data were abstracted by the primary and senior authors (P.K., M.H.S.).

\section{Assessment of Literature Quality and Treatment Recommendations}

The quality of the literature and thus the strength of treatment recommendations was assessed using definitions set forth by Woolf, et al.,$^{90}$ and used by Loblaw and Laperriere ${ }^{55}$ in their review of the literature on the metastatic spine. The definitions of the different classes of evidence denoting literature quality and strength of treatment recommendations are shown in Tables 1 and 2.

\section{Outcome Measures}

The primary outcome measure for this literature review was ambulatory status. In most articles this was reported directly, whereas in other articles this number was calculated from the neurological grading schemes that were used, such as the Frankel system (Table 3) ${ }^{26}$ Once the ambulatory status before and after treatment was deter-

\section{TABLE 1}

Classification of evidence on therapeutic effectiveness of treatments for metastatic spinal disease

\begin{tabular}{|c|c|}
\hline $\begin{array}{l}\text { Evidence } \\
\text { Class }\end{array}$ & Definition \\
\hline I & $\begin{array}{l}\text { evidence obtained from } \geq 1 \text { properly designed randomized } \\
\text { controlled trial }\end{array}$ \\
\hline II & $\begin{array}{l}\text { evidence obtained from well-designed, controlled trials w/o } \\
\text { randomization, such as nonrandomized cohort studies, case- } \\
\text { control studies, \& other comparable studies, including less } \\
\text { well-designed randomized controlled trials }\end{array}$ \\
\hline III & $\begin{array}{l}\text { evidence from case series, comparative studies w/ historical } \\
\text { controls, case reports, \& expert opinion, as well as signifi- } \\
\text { cantly flawed randomized controlled trials }\end{array}$ \\
\hline
\end{tabular}

TABLE 2

Classification of recommendations for treatment modalities in metastatic spinal disease

\begin{tabular}{cc}
\hline $\begin{array}{c}\text { Recom- } \\
\text { mendation }\end{array}$ & Criteria \\
\hline A & $\begin{array}{c}\text { good evidence (Class I) to support the recommendation that } \\
\text { the maneuver be specifically considered as an intervention } \\
\text { for the condition } \\
\text { fair evidence (Class II) to support the recommendation that } \\
\text { the maneuver be specifically considered as an intervention } \\
\text { for the condition } \\
\text { poor evidence (Class III) to support the recommendation that } \\
\text { the maneuver be specifically considered as an intervention } \\
\text { for the condition or that it confers no advantage over com- } \\
\text { peting interventions* } \\
\text { fair evidence (Class II) to support the recommendation that } \\
\text { the maneuver be excluded from consideration as an inter- } \\
\text { vention for the condition } \\
\text { good evidence (Class I) to support the recommendation that } \\
\text { the maneuver be excluded from consideration as an inter- } \\
\text { vention for the condition }\end{array}$ \\
&
\end{tabular}

* Considering efficacy of the intervention with regard to primary outcome, and side effects of the intervention. The physician may then want to take into consideration other outcomes, such as cost convenience, resource allocation, and other aspects of feasibility.

mined, we calculated two further variables in selected studies: the "success" and "rescue" rates. The success rate is defined as the proportion of all patients within the study who retained or regained ambulatory function after treatment. The rescue rate is the percentage of patients who were nonambulatory before treatment, but who regained the ability to walk, either with assistance or independently.

Secondary outcomes included pain, treatment-related morbidity, survival, and autonomic function. These outcomes were not universally reported in the literature reviewed here and will therefore only be mentioned with reference to specific articles.

\section{Steroid Medications}

\section{RESULTS}

Best Level of Evidence, Class I; Level of Recommendation, A. There is good evidence to support the use of steroid drugs in patients with newly diagnosed metastatic spinal disease causing spinal cord dysfunction. It should be noted that in patients with no history of cancer who present with an undiagnosed spinal mass, especially younger patients, steroid drugs should be avoided until the diagnosis is made. The reason for this is that for some tumors, particularly lymphomas and thymomas, steroid medications have an oncolytic effect that may cause a delay in diagnosis. ${ }^{9}$ Dexamethasone is the most widely used steroid, although methylprednisolone, which is more commonly prescribed in trauma, has also been used. Steroid drugs have been shown to reduce vasogenic edema, protect against lipid peroxidation and lipid hydrolysis, prevent ischemia and intracellular calcium accumulation, and support cellular energy metabolism. ${ }^{3}$

The optimal dosage of dexamethasone in metastatic spinal cord compression is controversial. Loading doses range from 10 to $100 \mathrm{mg}$, followed by 4 to $24 \mathrm{mg}$ four

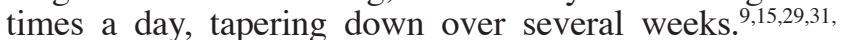


TABLE 3

Modified Frankel neurological functional classification

\begin{tabular}{cl}
\hline \hline Grade & \multicolumn{1}{c}{ Description } \\
\hline A & no motor or sensory function \\
B & preserved sensation only, no motor function \\
C & nonambulatory, wheelchair-bound, some motor function \\
a & bowel or bladder paralysis \\
b & neurogenic bowel or bladder \\
c & voluntary normal bowel or bladder function \\
D & ambulatory but w/ neurological symptoms \\
1 & requires walker \\
2 & requires cane \\
3 & can walk independently \\
a & bowel or bladder paralysis \\
b & neurogenic bowel or bladder \\
c & voluntary, normal bowel or bladder function \\
E & normal neurological function \\
\hline
\end{tabular}

57,64,78 Many practitioners use the larger doses for patients who present with severe baseline symptoms or worsening neurological examination. Some advocate using the trauma dose protocol in patients with rapid neurological deterioration. ${ }^{62}$ In a well-designed, randomized controlled study in which high-dose dexamethasone followed by radiotherapy was compared to radiotherapy alone, $81 \%$ of patients in the steroid treatment group were ambulatory posttreatment compared with $63 \%$ of patients treated with radiation alone. ${ }^{78}$ In another randomized controlled trial, patients with a complete myelographically confirmed block who received a $100-\mathrm{mg}$ bolus of dexamethasone followed by a standard maintenance dose had no better pain relief, ambulation, or bladder function compared with those who received a 10-mg bolus and the same maintenance therapy. ${ }^{84}$ It is clear, however, that higher doses are associated with more complications. ${ }^{39}$ Therefore, based on this information, an appropriate regimen of dexamethasone would be an initial bolus of $10 \mathrm{mg}$ followed by $16 \mathrm{mg} /$ day, tapering over several weeks.

\section{Surgery: Posterior Decompressive Laminectomy}

Best Level of Evidence, Class II; Level of Recommendation, D. For many years, laminectomy was the only surgical option offered to patients with metastatic spinal disease. In fact, in this context, the term "surgery" is to some extent still equated with laminectomy, contributing to the bias in favor of radiotherapy. One of the reasons laminectomy was the dominant surgical procedure was because of its relative ease. It can be performed quickly by any neurosurgeon with minimal intraoperative risk to the patient, and it does not require spinal column reconstruction or placement of internal stabilization devices. Despite its widespread use, there was no consensus among surgeons regarding its effectiveness. Some thought that it was the only reasonable hope for treating neurological deficits, whereas others found it to be of little value except for obtaining tissue to make a diagnosis and for relieving pain. ${ }^{10}$

Much of the existing literature on decompressive laminectomy consists of uncontrolled cohort studies (Class III). Recorded outcomes usually include ambulatory status before and after treatment, pain relief, and treatmentrelated complications. As can be seen in Table 4, 14 to
$58 \%$ of patients who underwent a posterior decompressive laminectomy were ambulatory postsurgery. Not shown in the table, however, are the significant nonneurological complications that follow laminectomy, specifically wound infection/dehiscence and spinal instability. In a review of the literature by Findlay, ${ }^{23}$ the incidence of nonneurological complications was found to be approximately $11 \%$.

In a number of articles, including controlled cohort studies (Class II), the efficacy of laminectomy alone has been compared with radiation alone and with laminectomy followed by radiation. ${ }^{10,18,23,29,58,77,79,92}$ One of these, by Gilbert, et al., ${ }^{29}$ was a single-institution, retrospective analysis of 235 patients treated with either decompressive laminectomy followed by radiation (65 patients) or radiation alone (170 patients). After treatment, $46 \%$ of those who underwent combination therapy were ambulatory compared with $49 \%$ of those who underwent radiation alone. Pretreatment neurological function was the most reliable indicator of posttreatment function. There was no significant difference in the rate of neurological recovery

TABLE 4

Ambulatory outcome after various treatments for spinal cord compression

\begin{tabular}{|c|c|c|c|}
\hline $\begin{array}{c}\text { Treatment } \\
\text { Authors \& Year }\end{array}$ & $\begin{array}{l}\text { No. of } \\
\text { Patients }\end{array}$ & $\begin{array}{l}\text { Success } \\
(\%)^{*}\end{array}$ & $\begin{array}{c}\text { Mean } \\
(\%)\end{array}$ \\
\hline \multicolumn{3}{|c|}{ posterior decompressive laminectomy alone } & 30 \\
\hline Barron, et al., 1959 & 38 & 29 & \\
\hline Wild \& Porter 1963 & 22 & 26 & \\
\hline Wright, 1963 & 21 & 14 & \\
\hline Brice \& McKissock, 1965 & 139 & 32 & \\
\hline Smith, 1965 & 52 & 25 & \\
\hline Auld \& Buerman, 1966 & 41 & 42 & \\
\hline Hall \& Mackay, 1973 & 129 & 30 & \\
\hline Livingston \& Perrin, 1978 & 100 & 58 & \\
\hline Baldini, et al., 1979 & 140 & 30 & \\
\hline Dunn, et al., 1980 & 104 & 33 & \\
\hline Stark, et al., 1982 & 32 & 16 & \\
\hline Findlay, 1987 & 80 & 24 & \\
\hline Sorensen, et al., 1989 & 105 & 34 & \\
\hline \multicolumn{3}{|l|}{ radiation therapy alone } & 47 \\
\hline Mones, et al., 1966 & 41 & 34 & \\
\hline Khan, et al., 1967 & 82 & 41 & \\
\hline Posner, 1971 & 75 & 47 & \\
\hline Cobb, et al., 1977 & 18 & 50 & \\
\hline Gilbert, et al., 1978 & 170 & 49 & \\
\hline Greenberg, et al., 1980 & 83 & 57 & \\
\hline Stark, et al., 1982 & 32 & 35 & \\
\hline Constans, et al., 1983 & 108 & 39 & \\
\hline Martenson, et al., 1985 & 42 & 64 & \\
\hline Ruff \& Lanska, 1989 & 41 & 73 & \\
\hline Sorensen, et al., 1990 & 149 & 38 & \\
\hline \multicolumn{3}{|c|}{ posterior decompressive laminectomy \& radiation therapy } & 47 \\
\hline Mullan \& Evans, 1957 & 21 & 43 & \\
\hline Wild \& Porter, 1963 & 23 & 44 & \\
\hline Wright, 1963 & 17 & 47 & \\
\hline Gilbert, et al., 1978 & 65 & 45 & \\
\hline Stark, et al., 1982 & 52 & 37 & \\
\hline Constans, et al., 1983 & 465 & 46 & \\
\hline Martenson, et al., 1985 & 21 & 57 & \\
\hline Sherman \& Waddell, 1986 & 111 & 57 & \\
\hline Sorensen, et al., 1990 & 91 & 53 & \\
\hline
\end{tabular}

* "Success" is defined as the ability to walk after the operation (that is, gait was maintained, improved, or regained as a result of the laminectomy). 
between the two groups. Of the 22 patients in whom rapidly progressive weakness developed ( $<48$ hours), nine underwent surgery and 13 received radiation therapy. None of the surgically treated patients improved, but seven of the patients who reveived radiation did. The authors' conclusions were that radiation should be the treatment of choice and that a decompressive laminectomy is indicated in only three situations: 1) to establish a diagnosis; 2) to treat a relapse if the patient is unable to undergo further radiation therapy; and 3) if symptoms progress during radiation treatment.

Despite the obvious need and repeated requests for investigators to conduct a randomized controlled trial, only one has been attempted. Young, et al., ${ }^{92}$ randomized patients who had a symptomatic epidural spinal lesion to groups receiving either laminectomy followed by radiotherapy or radiotherapy alone. Sixteen patients were randomized to the surgical arm, and 13 to the radiotherapy arm. No significant difference was found between the groups with respect to pain relief, ambulatory status, or sphincter function. There were no treatment-related complications for surgery or radiotherapy. The major limitation of their study, as the authors clearly stated, was that the patient group was too small for the au-thors to be able to detect a difference in the treatments. Rather, the major goal of that study was to demonstrate that a properly conducted randomized controlled trial was feasible.

As a result of these articles and others listed in Table 4, laminectomy was viewed as a procedure with minimal neurological benefit and significant morbidity, and it was determined that radiation should assume the primary treatment role. Indiscriminate use of decompressive laminectomy was prone to failure because in most cases the tumor lies ventral to the thecal sac. This makes it impossible to accomplish a meaningful decompression or tumor resection without significant retraction of the thecal sac. Furthermore, a laminectomy can cause or worsen preexisting spinal instability. This can lead to progressive deformity, which in turn can result in pain, more deformity, and neurological compromise. Based on these data, we believe that decompressive laminectomy alone without supplemental internal fixation should not be used in patients with metastatic spinal disease, except in cases in which the disease is strictly confined to the lamina and spinous process. Despite the evidence, however, this procedure continues to be performed by some surgeons. ${ }^{74}$

The results of decompressive laminectomy seem to be improved if internal fixation (for example, pedicle screws) and fusion are performed as well. In a review of 134 patients treated with either a laminectomy (111 patients) or laminectomy with stabilization (23 patients), Sherman and Waddell, ${ }^{75}$ found that the latter group had better posttreatment ambulatory status (92 compared with 57\%), sphincter function, and pain control, and less recurrent neurological dysfunction. These findings have been supported by others. ${ }^{7,44,47,62,67,75}$

\section{Surgery: Circumferential Spinal Cord Decompression}

Best Level of Evidence, Class I; Level of Recommendation, A. With the failure of laminectomy, the primary treatment for metastatic disease has been largely confined to radiation therapy. Nevertheless, a new philosophy on the surgical management of metastatic spinal disease has emerged. In his 1984 article, Findlay ${ }^{23}$ reviewed the small amount of data on anterior spinal surgery and found "dramatic results" with regard to neurological function, but warned that "... . it is unclear as to how often such success could be achieved." As surgeons realized the limitations of the laminectomy, they began to decompress the ventral spinal cord, which is the most common site of metastatic spread. Thus, a new treatment protocol began to emergecircumferential spinal cord decompression.

To achieve a circumferential decompression, surgical approaches must be tailored to the location of the tumor with respect to the spinal cord. The end result is to free the spinal cord of any malignant compression. Approaches can be broadly classified as anterior (for example, transthoracic or retroperitoneal) or posterior, including posterolateral trajectories (for example, laminectomy, transpedicular, costotransversectomy, or lateral extracavitary). In addition to spinal cord decompression, reconstruction and immediate stabilization of the spinal column form the pillars of surgical management today.

A large amount of literature has emerged over the last 20 years; this is summarized in Table 5. Although the articles on circumferential decompression are generally more detailed than their laminectomy counterparts, they still are uncontrolled cohort studies and thus represent Class III data. In one of the largest reports Sundaresan, et al., ${ }^{81}$ described their results in 80 patients who had solitary metastatic spinal lesions. Depending on the anatomical and radiological findings on the extent of the tumor, they used a variety of approaches: an anterior approach was used in 32 patients, a strictly posterior or posterolateral approach was used in eight, and a combined anteroposterior approach was used in 40 . Preoperatively, 48 patients (60\%) were ambulatory and $55(69 \%)$ experienced a significant amount of pain. Postoperatively, 78 (98\%) were ambulatory, including $94 \%$ of those who were initially nonambulatory. Pain was improved in 95\%, with $76 \%$ reporting complete relief. Although the overall survival duration was 30 months, there was a considerable range among the various tumor types. Patients with breast and renal cell carcinoma had a median survival duration of 36 months, compared with 15 and 12 months for gastrointestinal and unknown primary carcinoma, respectively.

Gokaslan, et al., ${ }^{31}$ reported their results with transthoracic vertebrectomy in 72 patients. Pain was improved in $92 \%$ of patients, and $93 \%$ were able to walk postoperatively. Of the 13 patients who were nonambulatory preoperatively, 10 regained ambulatory ability after surgery, with three of them regaining normal function. The 1-year survival rate for the entire cohort was $62 \%$. Overall, the data seem to indicate that neurological outcomes are far superior to those that are achieved with decompressive laminectomy and/or radiation. Not surprisingly, the morbidity and mortality rates associated with this more aggressive surgical management are significant (Table 5).

Analogous to the controversy of laminectomy compared with radiation in the "old era," it is clear that a randomized controlled trial is needed to address more adequately the question of the effectiveness of circumferential decompressive surgery compared with radiation in this "new era." At the 2003 annual meeting of the Amer- 
Treatment of metastatic spinal epidural disease

TABLE 5

Literature review of results of circumferential spinal cord decompression in patients with metastasis*

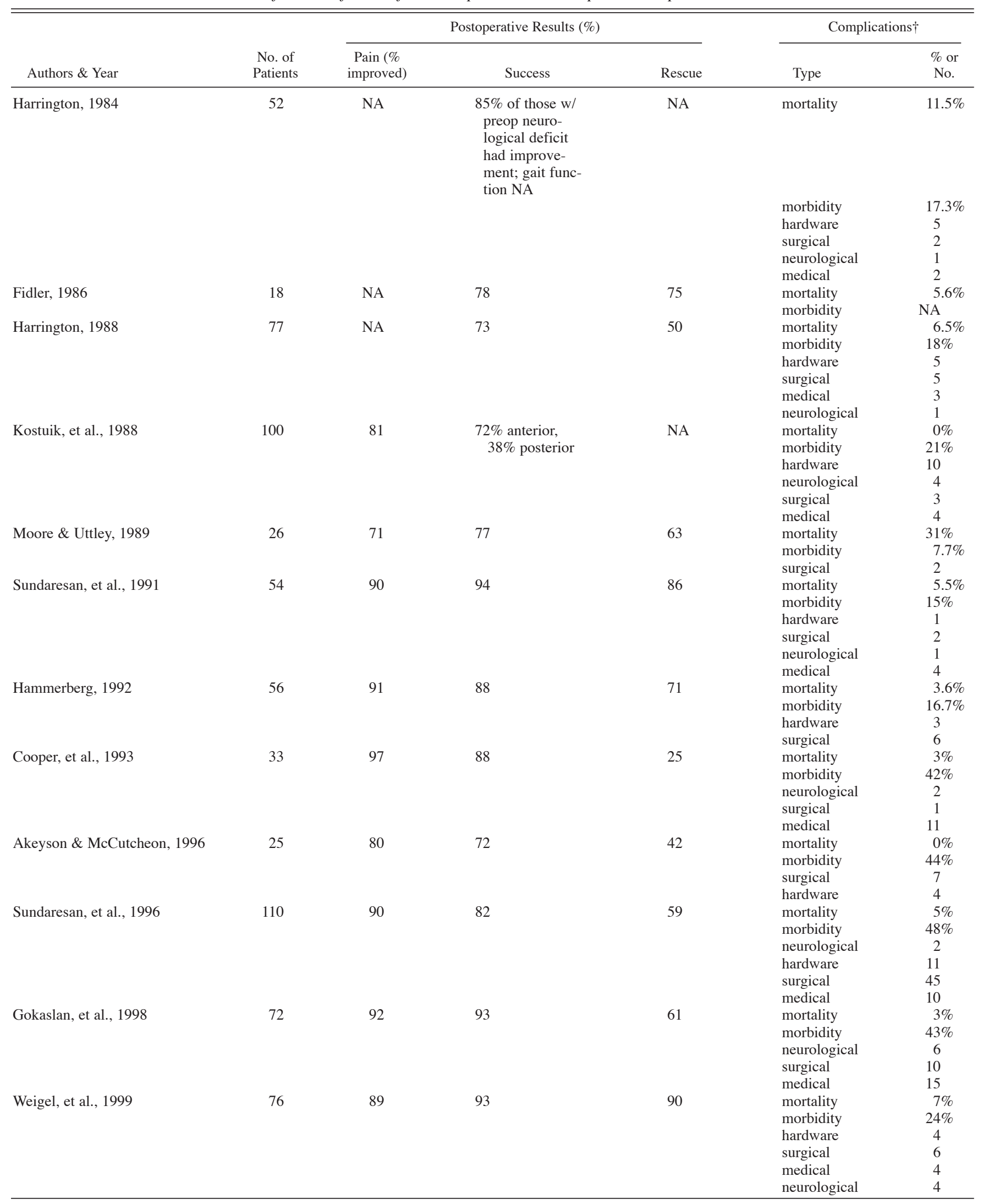


P. Klimo, J. R. W. Kestle, and M. H. Schmidt

TABLE 5, Continued

Literature review of results of circumferential spinal cord decompression in patients with metastasis*

\begin{tabular}{|c|c|c|c|c|c|c|}
\hline \multirow[b]{2}{*}{ Authors \& Year } & \multirow[b]{2}{*}{$\begin{array}{c}\text { No. of } \\
\text { Patients }\end{array}$} & \multicolumn{3}{|c|}{ Postoperative Results (\%) } & \multicolumn{2}{|c|}{ Complications $^{\dagger}$} \\
\hline & & $\begin{array}{c}\text { Pain (\% } \\
\text { improved) }\end{array}$ & Success & Rescue & Type & $\begin{array}{l}\% \text { or } \\
\text { No. }\end{array}$ \\
\hline Wise, et al., 1999 & 80 & NA & 89 & 41 & $\begin{array}{l}\text { mortality } \\
\text { morbidity } \\
\text { surgical } \\
\text { hardware } \\
\text { neurological } \\
\text { medical }\end{array}$ & $\begin{array}{l}2.5 \% \\
36 \% \\
9 \\
2 \\
2 \\
16\end{array}$ \\
\hline Bilsky, et al., 2000 & 25 & 100 & 88 & 0 & $\begin{array}{l}\text { mortality } \\
\text { mortality } \\
\text { surgical } \\
\text { neurological } \\
\text { medical }\end{array}$ & $\begin{array}{c}12 \% \\
32 \% \\
1 \\
2 \\
5\end{array}$ \\
\hline Hatrick, et al., 2000 & 42 & 90 & 86 & 57 & $\begin{array}{l}\text { mortality } \\
\text { morbidity } \\
\text { surgical } \\
\text { hardware } \\
\text { neurological }\end{array}$ & $\begin{array}{c}0 \\
19 \% \\
3 \\
2 \\
3\end{array}$ \\
\hline Fourney, et al., 2001 & 100 & 87 & 86 & 46 & $\begin{array}{l}\text { mortality } \\
\text { morbidity } \\
\text { surgical } \\
\text { hardware } \\
\text { neurological } \\
\text { medical }\end{array}$ & $\begin{array}{c}0 \\
65 \% \\
21 \\
3 \\
3 \\
19\end{array}$ \\
\hline Sundaresan, et al., 2002 & 80 & 95 & 98 & 94 & $\begin{array}{l}\text { mortality } \\
\text { morbidity } \\
\text { hardware } \\
\text { surgical } \\
\text { medical } \\
\text { neurological }\end{array}$ & $\begin{array}{l}1.3 \% \\
29 \% \\
4 \\
16 \\
2 \\
1\end{array}$ \\
\hline
\end{tabular}

* "Success" is defined as the proportion of patients who were ambulatory after treatment, whereas "rescue" is the proportion of nonambulatory patients who regained ambulatory function, either with assistance or independently. Abbreviations: NA = not available.

$\uparrow$ Mortality and morbidity are defined as occurrence of death or complication within 30 days of the operation. Morbidity is the number of complications divided by the number of patients in the study. Thus, overestimates may arise if one patient suffered more than one complication. The number of patients with each type of complication is recorded. Surgical complications include wound infection, hematomas, cerebrospinal fluid leaks, and so on. Examples of hardware complications include broken screws and graft migration/dislodgement. Medical complications are those that are not directly related to the surgery, such as pneumonia, myocardial infarction, deep venous thrombosis/pulmonary embolism, and so on. Patients who suffered new neurological deficits were considered to have neurological complications. Local recurrence and pseudarthrosis were not counted as complications.

ican Society of Clinical Oncology, Patchell, et al., ${ }^{63}$ presented the results of their randomized, controlled trial, in which they compared direct, decompressive resection followed by adjuvant radiation with conventional radiation alone. Both groups were treated with the same steroid protocol and both received the same total radiation dose (30 Gy). There were 50 patients in the surgical arm and 51 in the radiation arm of the study. Patients treated with surgery retained ambulatory and sphincter function significantly longer than patients in the radiation group. Also, $56 \%$ of nonambulatory patients in the surgical group regained the ability to walk, compared with $19 \%$ in the radiation group. Survival was not significantly different between the two groups.

This landmark study represents the first good Class I data in the metastatic spinal disease literature. Our review of the literature supports a change in the current management protocols for metastatic epidural spinal disease. Traditional indications for surgery include radiation-resistant tumors (sarcoma, lung, colon, and renal cell); obvious spinal instability; clinically significant neural compres- sion secondary to retropulsed bone or from spinal deformity; intractable pain unresponsive to medical treatment; and failure of radiation therapy (progression of deficit during treatment or spinal cord tolerance reached). We believe that surgery should be considered the primary treatment modality in all patients with newly diagnosed metastatic disease who do not have any of the indications for radiotherapy (see Conventional Radiation Therapy).

\section{Conventional Radiation therapy}

Best Level of Evidence, Class I; Level of Recommendation, A. Indications for radiotherapy are as follows: radiosensitive tumors (lymphoma, multiple myeloma, smallcell lung carcinoma, seminoma of testes, neuroblastoma, and Ewing sarcoma); expected survival less than 3 or 4 months; patient unable to tolerate an operation; total neurological deficit below the level of compression for more than 24 to 48 hours; and multilevel or diffuse spinal involvement. The standard radiation portal involves the diseased level with a 5-cm margin, which effectively includes two VBs above and below. ${ }^{53}$ The total radiation 
dosage is usually 3000 cGy (2000-4000 cGy) and is administered over a 10- to 14-day course, with higher doses delivered in the first few days and then tapered down. Patients with radiosensitive tumors (breast, myeloma, or lymphoma) have a better functional outcome overall than those who have more radiation-resistant tumors (sarcoma, lung, colon, or renal cell). In many patients the disease is isolated in the spine, usually the VB, without epidural compression. For these patients, a single dose (usually 8 Gy) provides good pain relief and is as efficacious as various fractionated regimens. ${ }^{42,43}$

Table 4 depicts the results of radiation therapy during the era in which decompressive laminectomy was the predominant surgical procedure. There have been a number of reports since then, all uncontrolled cohort studies, which are shown in Table 6. One of the largest reports is by Maranzano and colleagues. ${ }^{51,56,57}$ They treated 209 patients with radiation (30 Gy) and steroid drugs. Pain was present in $98 \%$ of patients and $65 \%$ had some degree of neurological dysfunction. The mean follow-up duration was 49 months. Pain improved in $71 \%$ of patients, ambulatory function improved in $36 \%$, and bladder function improved in $44 \%$. Overall, $76 \%$ recovered or preserved their ability to walk. The median survival duration for the whole group was 6 months, with a 1-year survival rate of $28 \%$. Favorable factors for survival included ambulatory status, both before and after treatment, and histological findings.

Helweg-Larsen ${ }^{40}$ followed 153 patients for a median of 2.6 months. Normal gait was present in 60 patients (39\%), assisted ambulation in $19(12 \%)$, paresis without gait function was found in $31(20 \%)$, and paraplegia was found in $43(29 \%)$. Neurogenic bladder was present in 57 patients $(37 \%)$. The total radiation dose was $28 \mathrm{~Gy}$, which was given in fractions of 4 Gy on 7 consecutive days. In total, 21 of the 74 initially nonambulatory patients (12 paretic, nine plegic) recovered some gait function. Seven patients (two with normal gait, five who needed assistance walking) deteriorated to a nonambulatory state because of treatment failure. Of those patients who presented with sphincter dysfunction, 10 (18\%) regained bladder function. The median survival duration was 5.4 months.

As stated previously, the recently released results of the first well-designed, randomized, controlled trial comparing stand-alone radiotherapy to surgery with adjuvant radiotherapy show a marked benefit for surgery. ${ }^{63}$ Thus, for

TABLE 6

Results of recent radiotherapy trials in patients with metastatic spinal disease

\begin{tabular}{lrrrrr}
\hline \hline & & & \multicolumn{2}{c}{$\begin{array}{c}\text { Postradiation } \\
\text { Results (\%) }\end{array}$} \\
\cline { 4 - 5 } \multicolumn{1}{c}{ Authors \& Year } & $\begin{array}{c}\text { No. of } \\
\text { Patients }\end{array}$ & $\begin{array}{c}\text { Pain (\% } \\
\text { improved) }\end{array}$ & \begin{tabular}{c} 
Success \\
\cline { 4 - 5 } Leviov, et al., 1993)
\end{tabular} & Rescue \\
\hline Maranzano \& Latini, 1995 & 209 & NA & 39 & 4 \\
Helweg-Larsen, 1996 & 153 & 83 & 76 & 51 \\
Katagiri, et al., 1998 & 101 & 57 & 64 & 28 \\
Chamberlain \& Kormanik, 1999 & 108 & 75 & NA & 5 \\
Rades, et al., 2002 & 98 & NA & 60 & NA \\
Zaidat \& Ruff, 2002 & 139 & 100 & 78 & 47 \\
\hline
\end{tabular}

patients who meet surgical criteria, the role of standard radiotherapy is as adjuvant therapy only. Conversely, there are many patients who either cannot tolerate surgery or in whom it would be inappropriate (for example, in highly radiosensitive tumors in patients with a short life expectancy). In these patients, radiation should still serve as the primary mode of treatment.

\section{Nonconventional Radiation Therapy}

Best Level of Evidence, Class III; Level of Recommendation, $\mathbf{C}$. With conventional external beam radiation, a significant amount of healthy tissue is exposed to radiation, including the spinal cord, which can lead to radiation-induced myelopathy. ${ }^{48,83,85}$ Therefore, if radiation could be delivered to the target while decreasing the amount delivered to healthy tissue, injuries to the spinal cord would theoretically be reduced. Nonconventional radiotherapy, which includes stereotactic radiosurgery and intensity-modulated radiotherapy, is able to do just that. The currently available data represent case series (Class III) evidence..$^{27,69-71}$ The follow up is short and outcome measures, such as neurological function, are rarely discussed. The research so far has shown nonconventional radiation therapy to be a safe intervention; however, its effectiveness has not been rigorously tested against other current therapies (surgery or conventional radiotherapy). Such data are needed before a treatment recommendation can be rendered.

\section{CONCLUSIONS}

Treatment of metastatic epidural spinal disease has undergone significant changes over the last 20 years. No longer is indiscriminant decompressive laminectomy offered as the only surgical treatment. It carries all the risks associated with an invasive procedure and offers the patient little benefit, unless it is used to remove tumors isolated in the posterior elements. From the existing literature we infer that surgery that frees the spinal cord at the site of compression, in addition to reconstructing and stabilizing the spinal column, is more effective at preserving and regaining neural function, notably ambulatory and sphincter function, than conventional radiotherapy. This type of surgery is also highly effective in relieving pain. The preliminary results of a recent randomized, controlled trial provide the first Class I evidence to support a reversal in the current trend toward primary treatment for many patients with metastatic disease. Conventional radiotherapy has a clearly defined role as adjuvant therapy, as well as primary therapy in those who are unable to tolerate or benefit significantly from surgery. The role of nonconventional radiation therapy, such as intensity-modulated radiotherapy and stereotactic radiosurgery, remains to be elucidated.

\section{References}

1. Adams M, Sonntag VKH: Surgical treatment of metastatic cervical spine disease. Contemp Neurosurg 23:1-5, 2001

2. Akeyson EW, McCutcheon IE: Single-stage posterior vertebrectomy and replacement combined with posterior instrumentation for spinal metastasis. J Neurosurg 85:211-220, 1996

3. Amar AP, Levy ML: Pathogenesis and pharmacological strate- 
gies for mitigating secondary damage in acute spinal cord injury. Neurosurgery 44:1027-1040, 1999

4. Auld AW, Buerman A: Metastatic spinal epidural tumors. An analysis of 50 cases. Arch Neurol 15:100-108, 1966

5. Baldini M, Tonnarelli GP, Princi L, et al: Neurological results in spinal cord metastases. Neurochirurgia 22:159-165, 1979

6. Barron KD, Hirano A, Araki S, et al: Experiences with metastatic neoplasms involving the spinal cord. Neurology 9: 91-106, 1959

7. Bauer HC: Posterior decompression and stabilization for spinal metastases. Analysis of sixty-seven consecutive patients. J Bone Joint Surg Am 79:514-522, 1997

8. Bilsky MH, Boland P, Lis E, et al: Single-stage posterolateral transpedicle approach for spondylectomy, epidural decompression, and circumferential fusion of spinal metastases. Spine 25: 2240-2250, 2000

9. Bilsky MH, Lis E, Raizer J, et al: The diagnosis and treatment of metastatic spinal tumor. Oncologist 4:459-469, 1999

10. Black P: Spinal metastasis: current status and recommended guidelines for management. Neurosurgery 5:726-746, 1979

11. Bohm P, Huber J: The surgical treatment of bony metastases of the spine and limbs. J Bone Joint Surg Br 84:521-529, 2002

12. Boriani S, Biagini R, De Iure F, et al: En bloc resections of bone tumors of the thoracolumbar spine. A preliminary report on 29 patients. Spine 21:1927-1931, 1996

13. Botterell EH, Fitzgerald GW: Spinal cord compression produced by extradural malignant tumours; early recognition, treatment and results. Can Med Assoc J 80:791-796, 1959

14. Brice J, McKissock W: Surgical treatment of malignant extradural spinal tumours. Br Med J 5446:1341-1344, 1965

15. Byrne TN: Spinal cord compression from epidural metastases. New Engl J Med 327:614-619, 1992

16. Chamberlain MC, Kormanik PA: Epidural spinal cord compression: a single institution's retrospective experience. Neurooncol 1:120-123, 1999

17. Cobb CA III, Leavens ME, Eckles N: Indications for nonoperative treatment of spinal cord compression due to breast cancer. J Neurosurg 47:653-658, 1977

18. Constans JP, de Divitiis E, Donzelli R, et al: Spinal metastases with neurological manifestations: review of 600 cases. J Neurosurg 59:111-118, 1983

19. Cook AM, Lau TN, Tomlinson MJ, et al: Magnetic resonance imaging of the whole spine in suspected malignant spinal cord compression: impact on management. Clin Oncol 10:39-43, 1998

20. Cooper PR, Errico TJ, Martin R, et al: A systematic approach to spinal reconstruction after anterior decompression for neoplastic disease of the thoracic and lumbar spine. Neurosurgery 32: $1-8,1993$

21. Dunn RC Jr, Kelly WA, Wohns RN, et al: Spinal epidural neoplasia. A 15-year review of the results of surgical therapy. J Neurosurg 52:47-51, 1980

22. Fidler MW: Anterior decompression and stabilisation of metastatic spinal fractures. J Bone Joint Surg Br 68:83-90, 1986

23. Findlay GF: Adverse effects of the management of malignant spinal cord compression. J Neurol Neurosurg Psychiatry 47: 761-768, 1984

24. Findlay GF: The role of vertebral body collapse in the management of malignant spinal cord compression. J Neurol Neurosurg Psychiatry 50:151-154, 1987

25. Fourney DR, Abi-Said D, Lang FF, et al: Use of pedicle screw fixation in the management of malignant spinal disease: experience in 100 consecutive procedures. J Neurosurg (Spine 1) 94:25-37, 2001

26. Frankel HL, Hancock DO, Hyslop G, et al: The value of postural reduction in the initial management of closed injuries of the spine with paraplegia and tetraplegia. I. Paraplegia 7: 179-192, 1969

27. Gertszten PC, Ozhasoglu C, Burton SA, et al: Feasibility of frameless single-fraction stereotactic radiosurgery for spinal lesions. Neurosurg Focus 13 (4):Article 2, 2002

28. Gerszten PC, Welch WC: Current surgical management of metastatic spinal disease. Oncology 14:1013-1024, 2000

29. Gilbert RW, Kim JH, Posner JB: Epidural spinal cord compression from metastatic tumor: diagnosis and treatment. Ann Neurol 3:40-51, 1978

30. Gokaslan ZL, York JE, Walsh GL, et al: Transthoracic vertebrectomy for metastatic spinal tumors. J Neurosurg 89: 599-609, 1998

31. Greenberg HS, Kim JH, Posner JB: Epidural spinal cord compression from metastatic tumor: results with a new treatment protocol. Ann Neurol 8:361-366, 1980

32. Hall AJ, Mackay NN: The results of laminectomy for compression of the cord or cauda equina by extradural malignant tumour. J Bone Joint Surg Br 55:497-505, 1973

33. Hammerberg KW: Surgical treatment of metastatic spine disease. Spine 17:1148-1153, 1992

34. Harrington KD: Anterior cord decompression and spinal stabilization for patients with metastatic lesions of the spine. J Neurosurg 61:107-117, 1984

35. Harrington KD: Anterior decompression and stabilization of the spine as a treatment for vertebral collapse and spinal cord compression from metastatic malignancy. Clin Orthop 233: 177-197, 1988

36. Harrington KD: Metastatic tumors of the spine: diagnosis and treatment. J Am Acad Orthop Surg 1:76-86, 1993

37. Hatrick NC, Lucas JD, Timothy AR, et al: The surgical treatment of metastatic disease of the spine. Radiother Oncol 56: 335-339, 2000

38. Healey JH, Brown HK: Complications of bone metastases. Cancer 88 (Suppl 12):2940-2951, 2000

39. Heimdal K, Hirschberg H, Slettebo H, et al: High incidence of serious side effects of high-dose dexamethasone treatment in patients with epidural spinal cord compression. J Neurooncol 12:141-144, 1992

40. Helweg-Larsen S: Clinical outcome in metastatic spinal cord compression. A prospective study of 153 patients. Acta Neurol Scand 94:269-275, 1996

41. Hirsh LF, Thanki AS, Spector HB: Spinal subdural metastatic adenocarcinoma: case report and literature review. Neurosurgery 10:621-625, 1982

42. Jeremic B: Single fraction external beam radiation therapy in the treatment of localized metastatic bone pain. A review. J Pain Symptom Manage 22:1048-1058, 2001

43. Jeremic B, Shibamoto Y, Acimovic L, et al: A randomized trial of three single-dose radiation therapy regimens in the treatment of metastatic bone pain. Int J Radiat Oncol Biol Phys 42: $161-167,1998$

44. Jonsson B, Sjostrom L, Olerud C, et al: Outcome after limited posterior surgery for thoracic and lumbar spine metastases. Eur Spine J 5:36-44, 1996

45. Katagiri H, Takahashi M, Inagaki J, et al: Clinical results of nonsurgical treatment for spinal metastases. Int J Radiat Oncol Biol Phys 42:1127-1132, 1998

46. Khan FR, Glicksman AS, Chu FC, et al: Treatment by radiotherapy of spinal cord compression due to extradural metastases. Radiology 89:495-500, 1967

47. Kluger P, Korge A, Scharf HP: Strategy for the treatment of patients with spinal neoplasms. Spinal Cord 35:429-436, 1997

48. Koehler PJ, Verbiest H, Jager J, et al: Delayed radiation myelopathy: serial MR-imaging and pathology. Clin Neurol Neurosurg 98:197-201, 1996

49. Kostuik JP, Errico TJ, Gleason TF, et al: Spinal stabilization of vertebral column tumors. Spine 13:250-256, 1988

50. Lada R, Kaminski HJ, Ruff RL: Metastatic spinal cord compression, in Vinken PJ, Bruyn GW, Vecht CJ (eds): Handbook of Clinical Neurology. Neuro-oncology, Part III. Neurological Disorders in Systemic Cancer. Amsterdam: Elsevier, 
1997, Vol 69, Rev. Ser. 25, pp 167-189

51. Latini P, Maranzano E, Ricci S, et al: Role of radiotherapy in metastatic spinal cord compression: preliminary results from a prospective trial. Radiother Oncol 15:227-233, 1989

52. Leviov M, Dale J, Stein M, et al: The management of metastatic spinal cord compression: a radiotherapeutic success ceiling. Int J Radiat Oncol Biol Phys 27:231-234, 1993

53. Linstadt DE: Spinal cord, in Leibel SA, Phillips TL (eds): Textbook of Radiation Oncology. Philadelphia: WB Saunders, 1998, pp 401-411

54. Livingston KE, Perrin RG: The neurosurgical management of spinal metastases causing cord and cauda equina compression. J Neurosurg 49:839-843, 1978

55. Loblaw DA, Laperriere NJ: Emergency treatment of malignant extradural spinal cord compression: an evidence-based guideline. J Clin Oncol 16:1613-1624, 1998

56. Maranzano E, Latini P: Effectiveness of radiation therapy without surgery in metastatic spinal cord compression: final results from a prospective trial. Int J Radiat Oncol Biol Phys 32: 959-967, 1995

57. Maranzano E, Latini P, Checcaglini F, et al: Radiation therapy in metastatic spinal cord compression. A prospective analysis of 105 consecutive patients. Cancer 67:1311-1317, 1991

58. Martenson JA Jr, Evans RG, Lie MR, et al: Treatment outcome and complications in patients treated for malignant epidural spinal cord compression (SCC). J Neurooncol 3:77-84, 1985

59. Mones RJ, Dozier D, Berrett A: Analysis of medical treatment of malignant extradural spinal cord tumors. Cancer 19: 1842-1853, 1966

60. Moore AJ, Uttley D: Anterior decompression and stabilization of the spine in malignant disease. Neurosurgery 24:713-717, 1989

61. Mullan J, Evans JP: Neoplastic disease of the spinal extradural space; a review of fifty cases. AMA Arch Surg 74:900-907, 1957

62. Olerud C, Jonsson B: Surgical palliation of symptomatic spinal metastases. Acta Orthop Scand 67:513-522, 1996

63. Patchell R, Tibbs PA, Regine WF, et al: A randomized trial of direct decompressive surgical resection in the treatment of spinal cord compression caused by metastasis. Proc Am Soc Clin Oncol 22:1, 2003 (Abstract)

64. Portenoy RK, Lipton RB, Foley KM: Back pain in the cancer patient: an algorithm for evaluation and management. Neurology 37:134-138, 1987

65. Posner JB: Spinal cord compression: a neurological emergency. Clin Bull 1:65-71, 1971

66. Rades D, Heidenreich F, Karstens JH: Final results of a prospective study of the prognostic value of the time to develop motor deficits before irradiation in metastatic spinal cord compression. Int J Radiat Oncol Biol Phys 53:975-979, 2002

67. Rompe JD, Hopf CG, Eysel P: Outcome after palliative posterior surgery for metastatic disease of the spine-evaluation of 106 consecutive patients after decompression and stabilisation with the Cotrel-Dubousset instrumentation. Arch Orthop Trauma Surg 119:394-400, 1999

68. Ruff RL, Lanska DJ: Epidural metastases in prospectively evaluated veterans with cancer and back pain. Cancer 63: 2234-2241, 1989

69. Ryu S, Yin FF, Rock J, et al: Image-guided and intensity-modulated radiosurgery for patients with spinal metastasis. Cancer 97:2013-2018, 2003

70. Ryu SI, Chang SD, Kim DH, et al: Image-guided hypo-fractionated stereotactic radiosurgery to spinal lesions. Neurosurgery 49:838-846, 2001

71. Ryu SI, Kim DH, Martin DP, et al: Image-guided spinal stereotactic radiosurgery. Tech Neurosurg 8:56-64, 2003

72. Schaberg J, Gainor BJ: A profile of metastatic carcinoma of the spine. Spine 10:19-20, 1985

73. Schijns OE, Kurt E, Wessels P, et al: Intramedullary spinal cord metastasis as a first manifestation of a renal cell carcinoma: report of a case and review of the literature. Clin Neurol Neurosurg 102:249-254, 2000

74. Schoeggl A, Reddy M, Matula C: Neurological outcome following laminectomy in spinal metastases. Spinal Cord 40: 363-366, 2002

75. Sherman RM, Waddell JP: Laminectomy for metastatic epidural spinal cord tumors. Posterior stabilization, radiotherapy, and preoperative assessment. Clin Orthop 207:55-63, 1986

76. Smith R: An evaluation of surgical treatment for spinal cord compression due to metastatic carcinoma. J Neurol Neurosurg Psych 28:152-158, 1965

77. Sorensen S, Borgesen SE, Rohde K, et al: Metastatic epidural spinal cord compression. Results of treatment and survival. Cancer 65:1502-1508, 1990

78. Sorensen S, Helweg-Larsen S, Mouridsen H, et al: Effect of high-dose dexamethasone in carcinomatous metastatic spinal cord compression treated with radiotherapy: a randomised trial. Eur J Cancer 30A:22-27, 1994

79. Stark RJ, Henson RA, Evans SJ: Spinal metastases. A retrospective survey from a general hospital. Brain 105:189-213, 1982

80. Sundaresan N, Digiacinto GV, Hughes JE, et al: Treatment of neoplastic spinal cord compression: results of a prospective study. Neurosurgery 29:645-650, 1991

81. Sundaresan N, Rothman A, Manhart K, et al: Surgery for solitary metastases of the spine: rationale and results of treatment. Spine 27:1802-1806, 2002

82. Sundaresan N, Steinberger AA, Moore F, et al: Indications and results of combined anterior-posterior approaches for spine tumor surgery. J Neurosurg 85:438-446, 1996

83. Tan B, Khor TH: Radiation myelitis in carcinoma of the nasopharynx. Clin Radiol 20:329-331, 1969

84. Vecht CJ, Haaxma-Reiche H, van Putten W, et al: Initial bolus of conventional versus high-dose dexamethasone in metastatic spinal cord compression. Neurology 39:1255-1257, 1989

85. Wara WM, Phillips TL, Sheline GE, et al: Radiation tolerance of the spinal cord. Cancer 35:1558-1562, 1975

86. Weigel B, Maghsudi M, Neumann C, et al: Surgical management of symptomatic spinal metastases. Postoperative outcome and quality of life. Spine 24:2240-2246, 1999

87. Wild WO, Porter RW: Metastatic epidural tumor of the spine. A study of 45 cases. Arch Surg 87:825-830, 1963

88. Wise JJ, Fischgrund JS, Herkowitz HN, et al: Complication, survival rates, and risk factors of surgery for metastatic disease of the spine. Spine 24:1943-1951, 1999

89. Wong DA, Fornasier VL, MacNab I: Spinal metastases: the obvious, the occult, and the impostors. Spine 15:1-4, 1990

90. Woolf SH, Battista RN, Anderson GM, et al: Assessing the clinical effectiveness of preventative maneuvers: analytic principles and systematic methods in reviewing evidence and developing clinical practice recommendations. A report by the Canadian Task Force on the Periodic Health Examination. J Clin Epidemiol 43:891-905, 1990

91. Wright RL: Malignant tumers in the spinal extradural space: results of surgical treatment. Ann Surg 157:227-231, 1963

92. Young RF, Post EM, King GA: Treatment of spinal epidural metastases. Randomized prospective comparison of laminectomy and radiotherapy. J Neurosurg 53:741-748, 1980

93. Zaidat OO, Ruff RL: Treatment of spinal epidural metastasis improves patient survival and functional state. Neurology 58: 1360-1366, 2002

Manuscript received September 16, 2003.

Accepted in final form October 10, 2003.

Address reprint requests to: Meic H. Schmidt, M.D., Department of Neurosurgery, University of Utah, 30 North 1900 East Suite 3B-409 SOM, Salt Lake City, Utah. email: meic.schmidt@ hsc.utah.edu. 